\title{
The Ability of Slags to Absorb Solid Oxide Inclusions
}

\author{
Martin VALDEZ, George S. SHANNON and Seetharaman SRIDHAR \\ Department of Materials Science and Engineering, Carnegie Mellon University, Pittsburgh, PA 15213, USA. E-mail: \\ sridhars@andrew.cmu
}

(Received on July 29, 2005; accepted on December 28, 2005)

\begin{abstract}
The capture rate of solid oxide-inclusion particles from molten steel by molten slag depends on the rate of steel film drainage (which occurs at certain particle velocities), interfacial separation, and dissolution into the slag. In this study the capture of common oxide inclusions of sizes $2.5-200 \mu \mathrm{m}$ and with velocities ranging from their terminal velocities to $0.3 \mathrm{~m} \cdot \mathrm{s}^{-1}$ approaching the interface between molten iron and slags with chemistries corresponding to ladle, tundish and mold slags are investigated. Calculations, based on a model available in literature, show that film drainage (when applicable) is rapid enough to be ignored. A sensitivity analysis based on the slag properties show that the interfacial energy between slag and inclusion is the most pertinent property that could hinder interfacial separation. However, the interfacial tension needed to achieve this has to be a minimum of $0.41 \mathrm{~N} / \mathrm{m}$ which is unreasonable for the case of common oxide inclusions such as $\mathrm{Al}_{2} \mathrm{O}_{3}, \mathrm{MgO}, \mathrm{ZrO}_{2}$ and $\mathrm{MgAl}_{2} \mathrm{O}_{4}$. The final step of dissolution was found based on studies with Confocal Scanning Laser Microscope experiments, to be significantly slower than the other steps. For a 100 $\mu \mathrm{m}$ particle, in the slags/inclusions investigated a correlation between slag viscosity, $\eta[\mathrm{Pa} \cdot \mathrm{s}]$ and super saturation, $\Delta C\left[\mathrm{~kg} \cdot \mathrm{m}^{-3}\right]$ with inclusion dissolution time, $\tau$ [s] was shown to be, $\tau=2.04 \cdot 10^{-2} /(C / \eta)$.
\end{abstract}

KEY WORDS: slags; physical propeties; inclusion separation; dissolution.

\section{Introduction}

Non-metallic inclusions in molten steels plague virtually every grade of continuously cast steel by reducing (i) process control due to clogging of nozzles during melt transfer and/or (ii) product quality due to defects that influence mechanical properties and corrosion resistance.

Inclusions in metallic melts are often removed by absorbing them into a slag phase. The slag phase is usually a molten mixture of $\mathrm{SiO}_{2}-\mathrm{Al}_{2} \mathrm{O}_{3}$ and metal oxides. In the case of steel manufacturing, this is done in the ladle furnace, tundish or continuous casting mold and involves three steps; (i) flotation of the inclusion to the steel melt/slag interface, (ii) separation into the slag phase and in some cases (iii) dissolution in the slag phase. Significant studies have been carried out to characterize the flow-fields in metallurgical reactors such as ladle, tundish and mold in order to predict and optimize the rates and trajectories of transport of inclusions from the molten steel to the steel/slag interface (see e.g. Refs. 1), 2)).

Among the three steps for inclusion removal, the second step involving separation across the interface is the least understood and is strongly influenced by both interfacial and bulk fluid properties. The thermodynamics of inclusion removal has been described in a number of papers. ${ }^{3-7)}$ For an inclusion to be removed it is necessary for it to travel through the slag/metal interface and on into the slag phase. In terms of interfacial energies, a favorable separation will be achieved, from a thermodynamic viewpoint, when the sum of changes in the various terms related to interfacial energies is favorable. While this model for separation of in- clusions across a metal/slag interface is based on thermodynamics, it is rather simplified and thus its applicability limited. This is primarily due to two significant issues. Firstly, inclusions are in general not thin. Thus during the separation, the interfacial energy of the system will change continuously (and abruptly) according to the changes in the interfacial areas between inclusion/slag, inclusion/steel, and steel/slag.

Secondly, at closer distances to the interface, the assumption of a continuous medium is no longer valid ${ }^{8,9)}$ and the thin liquid film ahead of the particle will be removed slower. The residence time of particles at a fluid/fluid interface may thus be long although it is energetically favorable to separate from one phase to another. In the case of solid inclusions, the film drainage is primarily a hydrodynamic problem and the subsequent separation depends largely on the interfacial capillary force. Bouris and Bergeles ${ }^{10)}$ and Nakajima and Okamura ${ }^{11)}$ describe models predicting the separation times for spherical, rigid and chemically inert particles.

The third step in inclusion removal is that of absorption into the slag phase. It might be argued that an inclusion is eliminated, once it is separated. Most common inclusions have a higher density than metallurgical slags, and therefore will rest at the interface. Depending on flow patterns, there is therefore always a risk of re-entrainment. ${ }^{12)}$ Also, for the case of mold slags, where a liquid film provides the lubrication at the mold/strand interface, un-dissolved solid particles are likely to have a detrimental effect. Valdez et al. ${ }^{13,14)}$, Sridhar and Cramb ${ }^{15)}$ and Fox et al. ${ }^{16)}$ used hightemperature confocal scanning laser microscopy (CSLM) to 
study the dissolution of different inclusion particles in tundish, ladle, and mould slags. These experiments were performed by placing oxide particles on the surface of slag samples that were designed to resemble industrial slags, except that the composition was tailored to maintain transparency after melting. The details of the CSLM can be found in $^{13-16)}$. The temperatures of the CSLM experiments shown in this paper were calibrated by melting slag and pure metals.

The current work aims at elucidating the mechanisms of inclusion capture by the slag after the inclusion reaches the interface and the effects of molten slag properties thereupon.

\section{Theoretical Background}

The Bouris/Bergeles and Nakajima/Okamura models consider a solid, spherical, chemically inert particle approaching a static interface. Depending on its velocity and therefore Reynolds number at time of impact, the inclusion can form a steel film of arbitrary thickness that must be drained by a stream function, before the particle comes into contact with the slag itself.

These models make several assumptions, namely that the steel-slag interface remains flat and static except in the case of the film formation, in which the film is concentric with the particle. They also assume there is no turbulence, the inclusion is perfectly rigid, and that all interfacial energies are constant.

The terminal rise velocity of a buoyant particle in fluid is given by

$$
U_{\text {term }}=\frac{2}{9} R_{\mathrm{I}}^{2}\left(\rho_{\mathrm{M}}-\rho_{\mathrm{I}}\right) \frac{g}{\eta_{\mathrm{M}}}
$$

$R_{\mathrm{I}}$ is the inclusion's radius, $g$ is acceleration due to gravity, $\eta_{\mathrm{M}}$ is the metal viscosity and $\rho_{\mathrm{M}}$ and $\rho_{\mathrm{I}}$ are the density of the metal and of the inclusion, respectively. The particle's Reynolds number is

$$
\operatorname{Re}=U \cdot 2 R_{\mathrm{I}} \cdot \rho_{\mathrm{M}} / \eta_{\mathrm{M}}
$$

where $U$ is the impact velocity, which will be equal to $U_{\text {term }}$ or higher. The streamline function is only limited by the size of the cap and the speed at which it is increasing due to the rising particle.

In both cases - impinging on the slag with a steel film, or in contact with both slag and steel - the particle's motion is dictated by a force balance between a capillary force $\left(F_{\sigma, Z}\right)$, a buoyancy force $\left(F_{\mathrm{b}}\right)$, a drag force $\left(F_{\mathrm{d}}\right)$, and a fluid-added mass force $\left(F_{\mathrm{m}}\right)$. The solution uses Newton's second law to determine the particle's overall acceleration. This is stepped over time to learn the particle position and speed.

In the case of a steel film formation, the force equations depend only on the effects of the steel melt and the impinging cap on the inclusion.

$$
F_{\sigma, Z}=4 \pi R_{\mathrm{I}}\left[\frac{\sigma_{\mathrm{MS}}}{2\left(R_{\mathrm{I}}+S\right)^{3}}\left(\left(2 R_{\mathrm{I}}+S-Z\right)(S+Z)\right)\right.
$$

$$
\begin{aligned}
& \left.+\frac{d Z}{d t} \frac{\eta_{\mathrm{S}}}{3} \frac{3}{2}\left(\frac{1}{R_{\mathrm{I}}+2 S}-\frac{1}{R_{\mathrm{I}}+4 S}\right)\left(1-\left(\frac{R_{\mathrm{I}}-Z}{R_{\mathrm{I}}+S}\right)^{3}\right)\right] \\
& F_{\mathrm{b}}=\frac{4}{3} \pi R_{\mathrm{I}}^{3}\left(\rho_{\mathrm{M}}-\rho_{\mathrm{I}}\right) g \\
& F_{\mathrm{d}}=6 \pi R_{\mathrm{I}} \eta_{\mathrm{M}} \frac{d Z}{d t} \\
& F_{\mathrm{m}}=\frac{1}{2} \frac{4}{3} \pi R_{\mathrm{I}}^{3} \rho_{\mathrm{M}} \frac{d^{2} Z}{d t^{2}}
\end{aligned}
$$

where $\sigma_{\mathrm{MS}}$ is the interfacial tension between metal and slag, while $Z, d Z / d t$, and $d^{2} Z / d t^{2}$ are the inclusion's position (starting at zero when the inclusion just reaches the interface), speed, and acceleration, $\eta_{\mathrm{S}}$ is the viscosity of the slag, and $S$ is the thickness of the steel film, which is initially at $0.002 \cdot R_{\mathrm{I}}$ and breaks at $0.001 \cdot R_{\mathrm{I}}$. Unfortunately, these values are somewhat arbitrary, and chosen simply to best match the original model developed by Nakajima and Okamura. ${ }^{11)}$ A better description would involve a hydrodynamic description of the interface and an instability criterion for the film rupture, but at this stage of investigation, the selection is made to involve a 'delay' caused by high Reynolds numbers.

In terms of effect, the capillary force tries to reject the inclusion, due to the creation of new area between the metal and slag. However, because the metal is quite non-viscous, the draining occurs fairly quickly, making this step of inclusion removal unimportant compared to the effect of inclusion-slag wetting.

The forces, when the particle is in contact with both steel and slag, are:

$$
\begin{aligned}
& F_{\sigma, Z}=\left(-2 \pi R_{\mathrm{I}}+2 \pi Z\right) \sigma_{\mathrm{MS}}+2 \pi R_{\mathrm{I}} \sigma_{\mathrm{SI}}-2 \pi R_{\mathrm{I}} \sigma_{\mathrm{MI}} \ldots . .(7) \\
& F_{\mathrm{b}}=\frac{4}{3} \pi R_{\mathrm{I}}^{3}\left(\rho_{\mathrm{S}} \tilde{\Delta}_{\mathrm{b}}-\rho_{\mathrm{I}}\right) g \\
& F_{\mathrm{d}}=6 \pi R_{\mathrm{I}} \eta_{\mathrm{S}} \tilde{B}_{2} \frac{d Z}{d t} \\
& F_{\mathrm{m}}=\frac{1}{2} \frac{4}{3} \pi R_{\mathrm{I}}^{3} \rho_{\mathrm{S}} \tilde{\Delta}_{\mathrm{b}} \frac{d^{2} Z}{d t^{2}}
\end{aligned}
$$

where $\rho_{\mathrm{I}}$ is the inclusion density, $\sigma_{\mathrm{SI}}$ and $\sigma_{\mathrm{MI}}$ are the interfacial tensions between slag and inclusion, and metal and inclusion, respectively, $\rho_{\mathrm{S}}$ is the density of the slag, and $\tilde{\Delta}_{\mathrm{b}}$ and are:

$$
\tilde{\Delta}_{\mathrm{b}}=\frac{1}{4}\left(\frac{\rho_{\mathrm{M}}}{\rho_{\mathrm{S}}}-1\right)\left(\frac{Z}{R_{\mathrm{I}}}\right)^{3}-\frac{4}{3}\left(\frac{\rho_{\mathrm{M}}}{\rho_{\mathrm{S}}}-1\right)\left(\frac{Z}{R_{\mathrm{I}}}\right)^{2}+\frac{\rho_{\mathrm{M}}}{\rho_{\mathrm{S}}}
$$




$$
\begin{gathered}
\tilde{B}_{2}=1 \text { for } \frac{Z}{R_{\mathrm{I}}} \geq 1, \\
\left(\frac{\eta_{\mathrm{M}}}{\eta_{\mathrm{S}}}-1\right)\left(\frac{Z}{R_{\mathrm{I}}}\right)^{2}-2\left(\frac{\eta_{\mathrm{M}}}{\eta_{\mathrm{S}}}-1\right)\left(\frac{Z}{R_{\mathrm{I}}}\right)+\frac{\eta_{\mathrm{M}}}{\eta_{\mathrm{S}}} \\
\text { for } 0 \leq \frac{Z}{R_{\mathrm{I}}} \leq 1 \ldots \ldots \ldots \ldots \ldots \ldots \ldots \ldots \ldots \ldots
\end{gathered}
$$

The capillary force, $F_{\sigma, \mathrm{Z}}$, appears to dominate the drive to separate-as expected, since an oxide inclusion would much prefer to be in contact with an oxide slag than the metal melt - and is dependent primarily on the interfacial tensions and areas between each of the phases, and will change as the respective areas change, as described in Eq. (7).

The buoyancy force, Eq. (8), depends on the densities between metal and inclusion, and between slag and inclusion, and includes a fractional term for particles that are in both phases $\left(\tilde{\Delta}_{\mathrm{b}}\right)$. This force is positive (upwards) if the inclusion is less dense than both of the liquid phases. However, note that the slag phase is typically less dense than a solid alumina inclusion. This would mean inclusions rest at the bottom of the slag phase after separating. The drag force, Eq. (9), depends on the viscosities of each of the liquid phases and the speed of the particle. The fluid-added mass force, Eq. (10), which dampens the particle's acceleration the way the drag force dampens the speed, depends on the acceleration and relative densities.

Since the inclusions rest at the bottom of the slag phase after separating from the metal, the dissolution in the slag is the final step towards eliminating any risk of the re-entrainment in the liquid metal.

In order to look into the possible governing dissolution mechanisms, the classical shrinking core reaction models are used. ${ }^{17)}$ The rate limiting steps considered are: Surface Reaction and Boundary Layer Diffusion in the Stokes regime. The equations governing both mechanisms are summarized in Table 1. The properties of interest are the particle density, the driving force for the dissolution, and depending on the controlling mechanism, the diffusion coefficient of the species that controls the dissolution process or the kinetic constant for the reaction.

In the case of surface reaction, the controlling mechanism is the dissolution reaction itself. On the other hand, when the surface reaction is fast, the slag in the interface is saturated with the components of the inclusions and, in order to continue with the dissolution process, diffusion would control the rate. As shown in Fig. 1, the driving force is the difference in concentration between the saturated slag and the bulk concentration.

If the change in radius of a particle with time is measured, the difference between a dissolution process controlled either by reaction kinetics or diffusion in the boundary layer, can be determined by the shape of the curve.

In order to reduce the scatter, the following criteria should be fulfilled: (i) Particle shape should be as close to spherical as possible, (ii) Dissolution process should be followed until the particle disappears, (iii) Rotation should be minimized $^{14)}$ and (iv) Bulk slag composition should remain
Table 1. Equations governing reaction and boundary layer dissolution mechanisms.

\begin{tabular}{||c|c|c||}
\hline MECHANISM & R VS. $t$ & $\tau$ \\
\hline Reaction & $R / R_{0}=1-(t / \tau)$ & $\tau=\rho \cdot R_{0} /\left[k_{I} \cdot\left(C^{(p)}-C^{(s)}\right)\right]$ \\
\hline Diffusion & $R / R_{0}=1-(t / \tau)^{1 / 2}$ & $\tau=\rho \cdot R_{0}{ }^{2} /\left[2 \cdot D \cdot\left(C^{(p)}-C^{(s)}\right)\right]$ \\
\hline
\end{tabular}

$\mathrm{R}$ and $\mathrm{R}_{0}$ : instant and initial radius, $t$ and $\tau$ : instant and total dissolution time, $\rho$ : density of the dissolving particle, $\mathrm{k}_{\mathrm{l}}$ : reaction rate constant, $\mathrm{C}^{(\mathrm{p})}-\mathrm{C}^{(\mathrm{s})}$ :concentration difference between the particle and the slag, and D: diffusion constant of the slowest diffusing species resulting from the dissolution process.

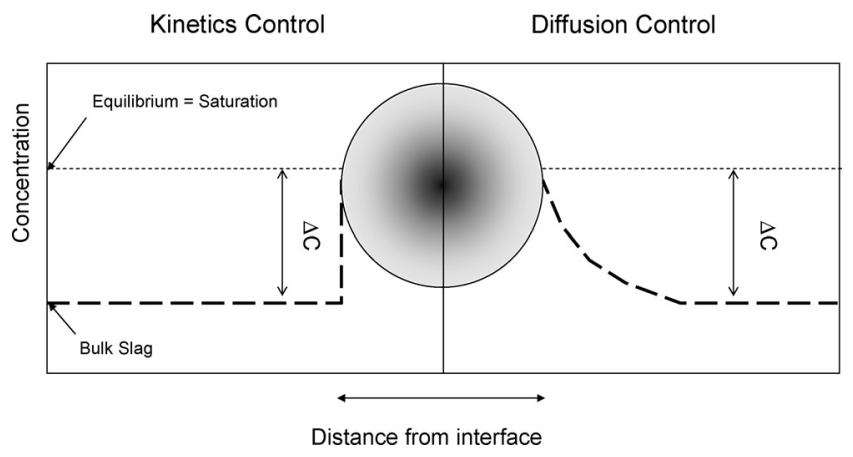

Fig. 1. Schematic of the driving force for the case of kinetics and diffusion control.

constant.

The Confocal Scanning Laser Microscope (CSLM) is a useful tool for studying dissolution of particles in slags. ${ }^{13-16)}$ The main advantages lie on the possibility of observing the dissolution process in-situ, by focusing on a particle placed inside a transparent slag. The laser microscope allows for high magnification and the use of small particles $(100 \mu \mathrm{m})$; this reduces the thermal gradients as well as keeps the slag composition constant. The high heating rate achieved by the gold image furnace, is useful to study systems in which dissolution rate are fast, minimizing dissolution during heating.

\section{Thermo-physical and Thermodynamic Properties and Kinetic Rates}

In this paper, alumina inclusions are used as a case study for the transfer trough the interface, defining the inclusion density and part of the interfacial tensions. The trends should however be valid for other common inclusions, such as: $\mathrm{Al}_{2} \mathrm{O}_{3}, \mathrm{MgO}, \mathrm{ZrO}_{2}$ and $\mathrm{MgAl}_{2} \mathrm{O}_{4}$. The steel melt is considered, for simplicity's sake, to be pure iron, and thus metal viscosity and again, part of the interfacial tensions are defined. The initial speed of the inclusion will be varied from the particle's terminal rise (Stokes) velocity in the metal (which depends on the size of the inclusion), up to a maximum expected flow velocity in the metal of $0.3 \mathrm{~m} / \mathrm{s}$.

Three separate slag phases are chosen for the analysis of the inclusions transfer to the slag-ladle, tundish, and mold slags. Not all differences will be discussed here, but one of the primary differences is that the tundish slag has a viscosity that is about an order of magnitude higher than the others. Table 2 lists the relevant properties for the slag phases, as well as for the steel melt and the inclusion used. Most are obtained from, or are confirmed by, the Slag Atlas. ${ }^{18)}$

With regards to the dissolution process, the slags are the same as in Table 2. The particles are Alumina $\left(\mathrm{Al}_{2} \mathrm{O}_{3}\right)$, Magnesium Oxide $(\mathrm{MgO})$, Spinel $\left(\mathrm{MgO}-\mathrm{Al}_{2} \mathrm{O}_{3}\right)$ and 
Table 2. Equations governing reaction and boundary layer dissolution mechanisms.

\begin{tabular}{|c|c|c|c|c|c|c|c|c|c|}
\hline & $\stackrel{\rho}{\mathrm{Kg} / \mathrm{m}^{3}}$ & \multicolumn{3}{|c|}{$\eta(\mathrm{Kg} / \mathrm{m} / \mathrm{s})$} & $\begin{array}{c}\sigma \\
\mathrm{N} / \mathrm{m}\end{array}$ & \multicolumn{4}{|c|}{ COMPOSITION (wt\%) } \\
\hline $\begin{array}{c}\text { Inclusion } \\
\text { Alumina }\end{array}$ & $3990^{3}$ & \multicolumn{3}{|c|}{---} & $\begin{array}{c}\sigma_{\text {IS }} \\
0.01- \\
0.2\end{array}$ & \multicolumn{4}{|c|}{$\mathrm{Al}_{2} \mathrm{O}_{3}: 100 \%$} \\
\hline $\begin{array}{l}\text { Metal } \\
\text { Iron }\end{array}$ & $7000^{3}$ & \multicolumn{3}{|c|}{$0.006^{3}$} & $\begin{array}{c}\sigma_{\mathrm{IM}} \\
1.504^{3}\end{array}$ & \multicolumn{4}{|c|}{$\mathrm{Fe}: 100 \%$} \\
\hline Slag: & & $\begin{array}{l}\text { Slag } \\
\text { Atlas }\end{array}$ & Urbain $^{4}$ & Riboud $^{4}$ & $\sigma_{\mathrm{MS}}$ & $\mathrm{SiO}_{2}$ & $\mathrm{CaO}$ & $\mathrm{Al}_{2} \mathrm{O}_{3}$ & $\mathrm{MgO}$ \\
\hline Ladle & $2700^{1}$ & $0.0562^{1}$ & 0.514 & 0.153 & $1.2^{1}$ & 5 & 59 & 36 & 0 \\
\hline Tundish & $2560^{1}$ & $0.6^{1}$ & 2.308 & 2.802 & $1.16^{1}$ & 42 & 36 & 21 & 0 \\
\hline $\begin{array}{c}\text { Tundish - } \\
\text { MgO }\end{array}$ & & -- & 1.293 & 1.239 & -- & 39.5 & 33 & 19.5 & 7.3 \\
\hline Mold & $2750^{1}$ & $0.0631^{2}$ & 0.439 & 0.111 & $1.12^{1}$ & 40.88 & 26 & 3.34 & $5.04^{5}$ \\
\hline
\end{tabular}

1 - Slag Atlas

2 - Fox, et al.

3 - Bouris/Bergeles.

4 - Mills.

5 - Contains in addition: $22.77 \% \mathrm{Na}_{2} \mathrm{O}, 1.77 \% \mathrm{~B}_{2} \mathrm{O}_{3}$

Zirconia $\left(\mathrm{ZrO}_{2}\right)$. All these particles could be found in the industrial process due to deoxidation and reoxidation processes $\left(\mathrm{Al}_{2} \mathrm{O}_{3}\right)$, and refractory erosion $(\mathrm{MgO}, \mathrm{MgO}-$ $\mathrm{Al}_{2} \mathrm{O}_{3}$ and $\mathrm{ZrO}_{2}$ ).

In order to analyze the results and to explain the rates measured in the CSLM, several thermo-physical and thermodynamic properties of the different slag metal systems needs to be determined. When the dissolution process is controlled by diffusion, as is found in most of the cases, and the Stokes-Einstein relation is used for estimating the diffusion coefficient, the total dissolution time $(\tau)$ according to the equation in Table 1 will be:

$$
\tau=\frac{\rho \cdot R_{0}^{2} \cdot 3 \pi a \eta}{2 k T \Delta C}
$$

for a given temperature and particle size:

$$
\tau \approx \frac{\rho a \eta}{\Delta C}
$$

where $\rho$ is the particle density, $D$ is the diffusion coefficient of the specie that controls the dissolution process and $\Delta C$ is the driving force for the dissolution, $k$ is the Boltzmann constant, $T$ is the temperature, a is the ionic diameter and $\eta$ is the viscosity of the slag.

It is clear from this simple equation, that in order to determined the parameters involved in the dissolution process it is necessary to have accurate description of the phase diagrams to evaluate $\Delta C$, and experimental data or models for the estimation of slag density and viscosity.

As an example, consider the dissolution of $\mathrm{Al}_{2} \mathrm{O}_{3}$ in the tundish slag (Table 2). This case can be analyzed by examining the $\mathrm{CaO}-\mathrm{Al}_{2} \mathrm{O}_{3}-\mathrm{SiO}_{2}$ phase diagram (Fig. 2). The equilibrium slag composition is found by identifying the saturation compositions of the bulk slag with the components from the particle. For systems more complicated, several phase diagrams are needed and in the case of a multi component slag, isopleths for compositions ranging from the bulk slag to that of the particle has to be generated in order to determine the slag saturation composition. ${ }^{16}$

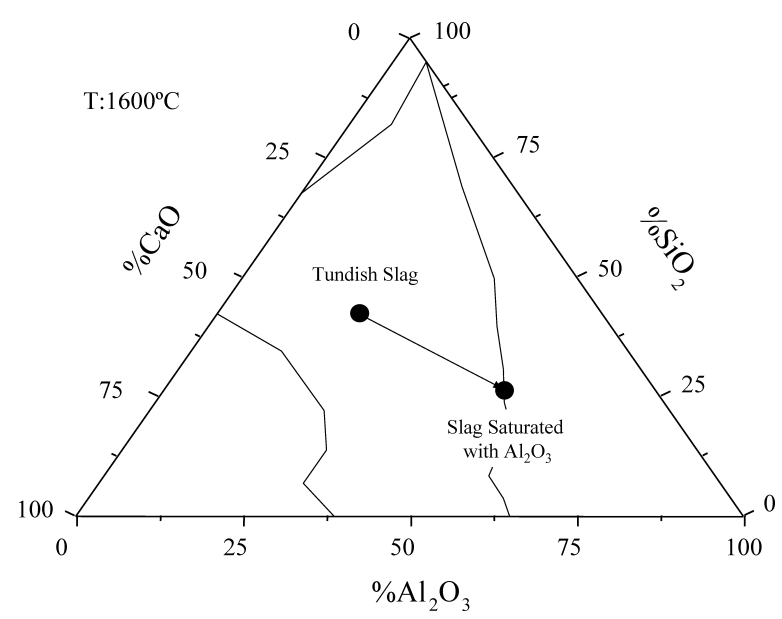

Fig. 2. Schematic of the determination of the saturation slag for the dissolution of $\mathrm{Al}_{2} \mathrm{O}_{3}$ in tundish slag at $1600^{\circ} \mathrm{C}$.

Table 2 also shows that there is great scatter in the viscosity of the slags when different sources or models are used. This makes almost impossible to actually calculate the accurate dissolution time, but allows for the determination of relative values for different slags/particle systems.

\section{Results and Discussion}

One of the primary purposes in the modeling of inclusion separation is to determine likely situations where inclusions will remain at the interface. These situations are dangerous because of the possibility of the inclusion being re-entrained back into the metal, so, it would be helpful to (i) determine which properties cause this situation, and (ii) find the limits on those properties where inclusion settling does occur. The primary properties involved in the model that are to be examined are the particle size, the particle's velocity when it reaches the steel/slag interface, the interfacial tension between the slag and the inclusion, and the slag viscosity.

Figure 3 shows separation curves for three different size inclusions, for three values of the interfacial tension between the inclusion and the slag $\left(\sigma_{\mathrm{IS}}\right)$. The low value 


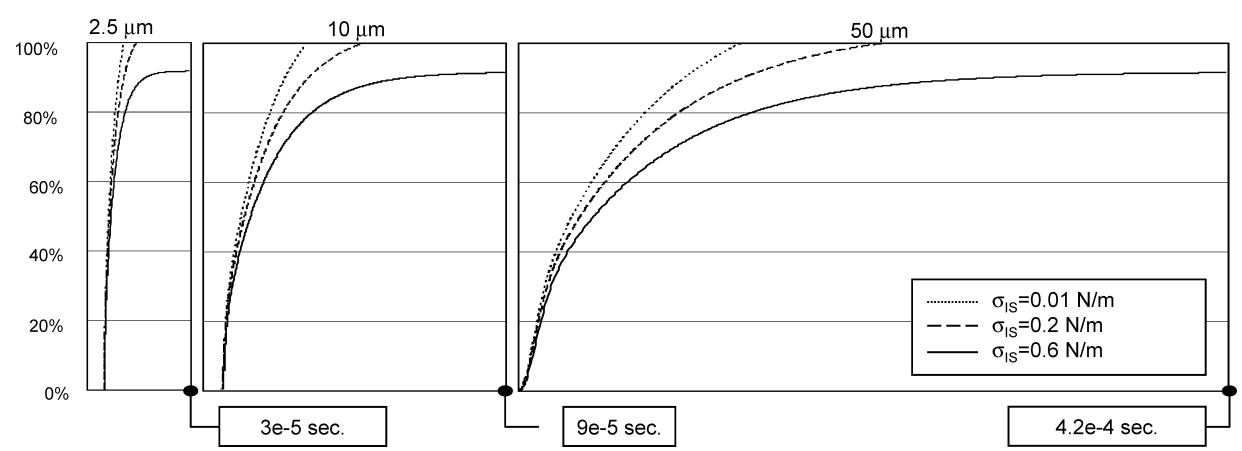

Fig. 3. The normalized separation of inclusions of different radii in a tundish slag, reaching the interface at terminal velocity, varying $\sigma_{\mathrm{IS}}$. Each chart starts from zero, and has the same scale.

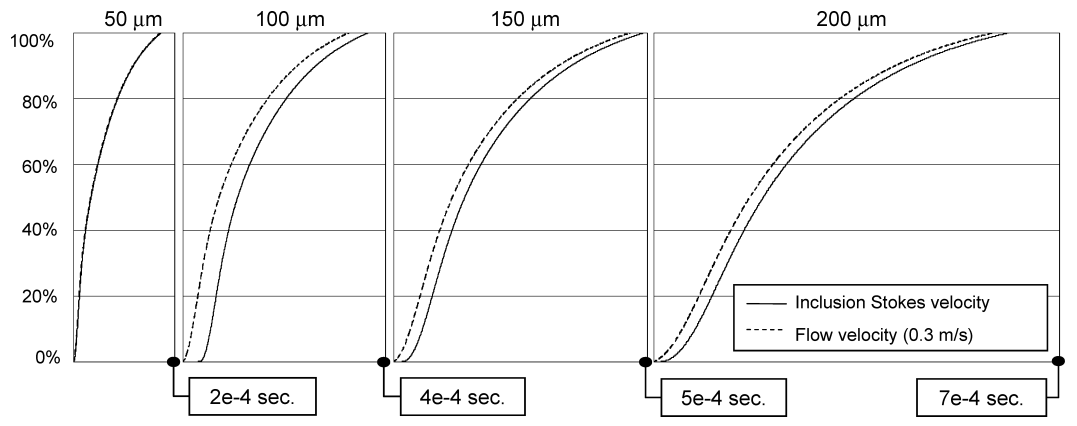

Fig. 4. The normalized separation of inclusions of different radii in a tundish slag with $\sigma_{\mathrm{IS}}=0.2 \mathrm{~N} / \mathrm{m}$, reaching the interface with two different velocities. Each chart starts from zero, and has the same scale.

$(0.01 \mathrm{~N} / \mathrm{m})$ was chosen under the assumption that the slag, at least once dissolution has caused a composition change towards equilibrium, will prefer to wet the inclusion as much as possible. An upper limit can be calculated using Young's Equation and contact angle and surface tension data available in literature. The Slag Atlas ${ }^{18)}$ gives a surface energy for solid alumina as $0.650 \mathrm{~N} \cdot \mathrm{m}^{-1}$ and a surface energy for the calcia-alumina-silica tundish slag as 0.474 $\mathrm{N} \cdot \mathrm{m}^{-1}$. Reported contact angles between molten slag droplets and oxide substrates are relatively scarce. The contact angle of a slag of similar composition $(30.6 \% \mathrm{CaO}-$ $37 \% \mathrm{Al}_{2} \mathrm{O}_{3}-32.4 \% \mathrm{SiO}_{2}$ ) on $\mathrm{Al}_{2} \mathrm{O}_{3}$ was however measured by Towers. ${ }^{19,20)}$ The contact angle is 18 degrees at the beginning of the experiment and changes to 8 degrees over a period of a few minutes. This gives us a $\sigma_{\text {IS }}$ of 0.18 to 0.2 $\mathrm{N} \cdot \mathrm{m}^{-1}$. The latter value is chosen as an upper limit on $\sigma_{\text {IS }}$, which is then varied to see its effect on the separation behavior. A large, unreasonable value of $0.6 \mathrm{~N} \cdot \mathrm{m}^{-1}$ was chosen to demonstrate the formation of a local energy minimum, where the inclusion comes to rest at only partial separation. This is discussed in more detail below.

As can be seen in the Fig. 3, the lowest $\sigma_{\text {IS }}$ value provides more of a driving force - in the form of the capillary force, $F_{\sigma, Z}$, thus the inclusion separates faster. All inclusion sizes seem to react similarly and have very similar separation curves.

Modifying the initial inclusion speed appears to have very little effect on actual separation. Plots varying the approach speed, from a particle's terminal rise velocity (typically $10^{-3}$ to $10^{-4} \mathrm{~m} \cdot \mathrm{s}^{-1}$ ) to $0.3 \mathrm{~m} \cdot \mathrm{s}^{-1}$, are nearly identical for inclusions less than $50 \mu \mathrm{m}$ in radius within the slags described. The capillary force appears to quickly determine the separation speed of the inclusion. Only for very large

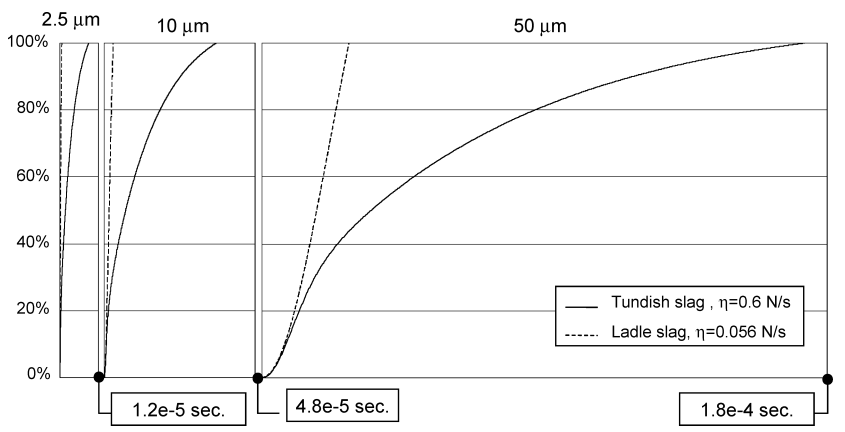

Fig. 5. The normalized separation of inclusions of different radii in two different slags, reaching the interface at terminal velocity. Each chart starts from zero, and has the same scale.

particles or very viscous slags does the initial speed have an effect on the separation behavior, due to the steel film formation.

Figure 4, for a tundish slag (the most viscous of the three) with $\sigma_{\text {IS }}=0.2 \mathrm{~N} \cdot \mathrm{m}^{-1}$, shows this effect-note that at a large enough particle size, the particle at terminal velocity lingers initially at the interface due to the lack of momentum to assist the drainage of steel film, as happens with the particle traveling much faster. However, as the particle radius increases beyond the typical range of inclusions, the effect of the initial delay decreases.

Compared to the tundish slag, the ladle slag and mold slag are less viscous by about an order of magnitude. A lower viscosity allows the particle to move more easilythat is, there is a reduction in the drag force, $F_{\mathrm{d}}$, thus the capillary force dominates even more strongly. Figure 5 shows the difference in separation for the ladle and tundish slag, using a $\sigma_{\text {IS }}$ of $0.2 \mathrm{~N} \cdot \mathrm{m}^{-1}$ and the particle's terminal 
velocity, for particles of differing size. Because the mold slag and ladle slag have very similar viscosities, their separation curves are extremely similar as well for these cases. As can be seen in the figure, increasing viscosity causes the inclusion to require much more time to separate.

Since the capillary force appears to provide nearly all of the driving force for separation, increasing $\sigma_{\text {IS }}$ (which determines the interfacial energy at the 'end point' of separation, that is, how 'downhill' the energy reduction is) will lessen the driving force for separation. Increasing this property further in the model eventually causes the inclusion to settle - it reaches a local energy minimum in late-stage separation where the cost of creating new slag/metal area is more than the reduction from removing inclusion/metal area. A $\sigma_{\text {IS }}$ value of $0.6 \mathrm{~N} \cdot \mathrm{m}^{-1}$ causes typical inclusions to settle about $90-95 \%$ separated, depending on the particular slag. For the tundish slag, a $\sigma_{\text {IS }}$ value of $0.41 \mathrm{~N} \cdot \mathrm{m}^{-1}$ is required for the inclusion to settle just at the edge of the interface. The inclusion settles at this position regardless of its size (tested for a $1 \mu \mathrm{m}, 10 \mu \mathrm{m}$, and $50 \mu \mathrm{m}$ radius inclusion) or its initial speed (tested from the inclusion's terminal velocity and $\left.0.3 \mathrm{~m} \cdot \mathrm{s}^{-1}\right)$.

The ladle and mold slags allow the particle to move more easily - that is, there is a reduction in the drag force, $F_{\mathrm{d}}$, thus the capillary force dominates even more strongly. So strongly, in fact, that the local energy minimum can be 'missed' initially, due to the inclusion's momentum, and the particle will separate without getting caught in its minimum. If the inclusion slows enough in time, it will move towards that minimum, oscillating until settling reduces its velocity to zero. Ladle and mold slags, therefore, require a $\sigma_{\text {IS }}$ of around $0.8 \mathrm{~N} \cdot \mathrm{m}^{-1}$ to keep the inclusion from 'missing' the minimum (here, around $82 \%$ ) and fully separating on its initial movement into the slag.

Because both $F_{\mathrm{d}}$ and $F_{\sigma, Z}$ vary with inclusion size, different behavior is noted for different size inclusions for ladle and mold slags. Larger inclusions enter the slag without settling or oscillating, while small inclusions settle without oscillation, implying that the inclusion's momentum is harder to overcome for the larger particle.

Both $\sigma_{\mathrm{IS}}=0.8 \mathrm{~N} \cdot \mathrm{m}^{-1}$ for ladle $/ \mathrm{mold}$ settling and $\sigma_{\mathrm{IS}}=$ $0.41 \mathrm{~N} \cdot \mathrm{m}^{-1}$ for tundish settling seem to be unreasonably high for an alumina inclusion, especially if dissolution causes local interfacial tension between inclusion and slag to drop. Therefore it seems unlikely that settling would occur in this manner. Theoretically, the conditions that must be met for settling are: (i) a local interfacial energy minimum, located at a percentage separation unrelated to size or other material properties, and (ii) a specific relation between slag viscosity (high to discourage large momentum) and particle size (low to reduce the actual $F_{\mathrm{d}}$ ) that allows that minimum to be reached without overshot.

Given this relation, the tundish slag has a high enough viscosity that all the particles thus far examined manage to settle with oscillation. Modeling the separation of an inclusion with a radius of $475 \mu \mathrm{m}$ (perhaps unreasonably large) in a tundish slag with $\sigma_{\mathrm{IS}}=0.6 \mathrm{~N} \cdot \mathrm{m}^{-1}$ reveals that such a particle would, indeed, nearly separate, then retreat towards the local energy minimum in an oscillation similar to those described above, and eventually settle at a fraction of its full separation equal to that of any other size particle. Particles larger than this have enough momentum that they separate before retreating to the energy minimum. The ladle slag, again using $\sigma_{\mathrm{IS}}=0.6 \mathrm{~N} \cdot \mathrm{m}^{-1}$, requires a maximum particle size of about $4 \mu \mathrm{m}$ to allow settling with its particular viscosity. These $\sigma_{\text {IS }}$ values are probably unreasonably high, so settling seems unlikely using alumina inclusionsthough there are several un-modeled possibilities. The local interfacial energy minimum is a function of the other interfacial tensions as well-if these change, due to local surface effects or compositional changes or alternate inclusion compositions, such a minimum may be possible, and perhaps even 'deep' enough for re-entrainment back into the steel more likely. Also note that spheres are the only shape examined here. It is possible for different shapes to naturally have minimums caused by the particular distribution of areas.

It is also interesting to notice, that the dissolution of the particle in the slag may also change the shape of the inclusion. Since a dissolution process will tend to reduce the area of the inclusions in contact with the slag and, the dissolution will also tend to decrease the surface tension of the slag/particle interface, ${ }^{19)}$ the particle will move into the slag during dissolution.

An example of dissolution experiments for a $100 \mu \mathrm{m}$ $\mathrm{Al}_{2} \mathrm{O}_{3}$ particle in the tundish slag can be found in the literature. $^{13,14)}$ The total dissolution time for this particle was around $4 \mathrm{~min}$. When the same type of particle was tested on the mold slag, the dissolution at $1500^{\circ} \mathrm{C}$ was so fast; it was not possible to reach the experimental temperature before the particle has completely disappeared.

Our objective is to be able to explain these variations in dissolution rate using the Eq. (12). The saturated slags for the system studied were calculated using the information available in the Slag Atlas ${ }^{18)}$ and from isopleths calculated with MTDATA. ${ }^{16)}$ The results are shown in Table 3.

Table 3. Slag Saturation Composition (weight percent).

\begin{tabular}{|c|c|c|c|c|c|c|c|c|}
\hline \multirow{2}{*}{ Component } & \multicolumn{2}{|c|}{ Tundish } & \multirow{2}{*}{$\begin{array}{c}\text { Tundish - } \mathrm{MgO} \\
\text { Sat- } \mathrm{Al}_{2} \mathrm{O}_{3} \\
\end{array}$} & \multirow{2}{*}{$\begin{array}{c}\text { Ladle } \\
\text { Sat- } \mathrm{Al}_{2} \mathrm{O}_{3} \\
\end{array}$} & \multicolumn{4}{|c|}{ Mould } \\
\hline & Sat- $\mathrm{Al}_{2} \mathrm{O}_{3}$ & Sat-MgO & & & Sat- $\mathrm{Al}_{2} \mathrm{O}_{3}$ & Sat- $\mathrm{ZrO}_{2}$ & Sat-MgO & Sat-Spinel \\
\hline $\mathrm{SiO}_{2}$ & 32 & 36 & 31.5 & 2.5 & 27.39 & 39.33 & 37.20 & 31.05 \\
\hline $\mathrm{CaO}$ & 26 & 31 & 26.7 & 34.5 & 17.54 & 25.19 & 23.83 & 19.88 \\
\hline $\mathrm{Al}_{2} \mathrm{O}_{3}$ & 42 & 18 & 34.5 & 63 & 35.2 & 3.21 & 3.04 & 19.79 \\
\hline $\mathrm{MgO}$ & 0 & 15 & 7.3 & 0 & 3.38 & 4.85 & 13.61 & 10.64 \\
\hline $\mathrm{Na}_{2} \mathrm{O}$ & 0 & 0 & 0 & 0 & 15.26 & 21.91 & 20.72 & 17.29 \\
\hline $\mathrm{B}_{2} \mathrm{O}_{3}$ & 0 & 0 & 0 & 0 & 1.19 & 1.7 & 1.61 & 1.34 \\
\hline $\mathrm{ZrO}_{2}$ & 0 & 0 & 0 & 0 & 0 & 3.96 & 0 & 0 \\
\hline
\end{tabular}


Table 4. Viscosity (Riboud)-dissolution time and interface composition. ${ }^{13-16)}$

\begin{tabular}{||c|c|c|c|c|c|c|c|c|c|c||}
\hline \hline Particles & \multicolumn{3}{|c|}{$\mathrm{Al}_{2} \mathrm{O}_{3}$} & $\mathrm{MgO}$ & $\mathrm{MgO}$ & $\mathrm{ZrO}_{2}$ & \multicolumn{3}{c||}{ Spinel Particles } \\
\hline Slag & Tundish & Tundish-MgO & Ladle & Mould & Tundish & Mould & Mould & \multicolumn{3}{c||}{ Mould } \\
\hline Diffusing Species & \multicolumn{3}{|c|}{$\mathrm{Al}_{2} \mathrm{O}_{3}$} & $\mathrm{MgO}$ & $\mathrm{MgO}$ & $\mathrm{ZrO}_{2}$ & $\mathrm{MgAl}_{2} \mathrm{O}_{4}$ & $\mathrm{Al}_{2} \mathrm{O}_{3}$ & $\mathrm{MgO}^{\prime}$ \\
\hline$\Delta \mathrm{C}$ & 0.0748 & 0.0530 & 0.0994 & 0.1219 & 0.0664 & 0.0349 & 0.0164 & 0.1242 & 0.0638 & 0.0209 \\
\hline$\mu$ & 2.8028 & 1.2394 & 0.1535 & 0.1111 & 2.8028 & 0.1111 & 0.1111 & 0.1111 & 0.1111 & 0.1111 \\
\hline$\Delta \mathrm{C} / \mu$ & 0.0267 & 0.0428 & 0.6479 & 1.0964 & 0.0237 & 0.3141 & 0.1472 & 1.1183 & 0.5740 & 0.1879 \\
\hline Temperature $\left({ }^{\circ} \mathrm{C}\right)$ & \multicolumn{3}{|c|}{$1450-1530$} & 1400 & $1450-1530$ & 1500 & & 1400 \\
\hline $\mathrm{t}$ (sec.) - $100 \mu \mathrm{m}$ & 225 & 235 & 75 & 28 & 103 & 150 & 270 & & 250 \\
\hline Interface & $\mathrm{Al}_{2} \mathrm{O}_{3}$ & Spinel & $\mathrm{Al}_{2} \mathrm{O}_{3}$ & $\mathrm{Al}_{2} \mathrm{O}_{3}$ & $\mathrm{MgAl}_{2} \mathrm{O}_{4}$ & $\mathrm{MgO}$ & $\mathrm{ZrO}_{2}$ & \multicolumn{3}{c||}{$\mathrm{MgAl}_{2} \mathrm{O}_{4}$} \\
\hline
\end{tabular}

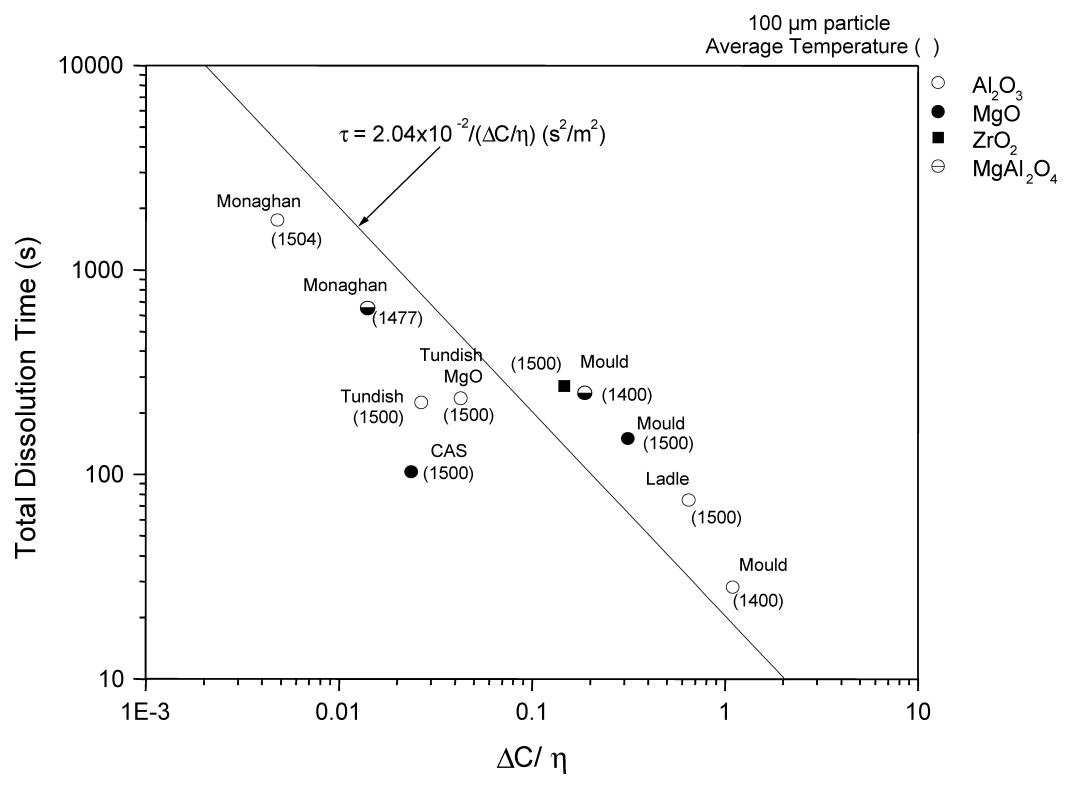

Fig. 6. Dissolution time for a $100 \mu \mathrm{m}$ particle in different slags as a function of $\Delta C / \eta$.

The driving force for dissolution is the difference in concentration between the bulk and the saturation composition for the dissolving species. The dissolution of the spinel particles put $\mathrm{Al}_{2} \mathrm{O}_{3}$ and $\mathrm{MgO}$ in the slag and then, the process can be controlled by the diffusion of either of these species. The diffusion of the aluminum anion $\left(\mathrm{AlO}_{3}^{3-}\right)$ is much smaller than the diffusion of the magnesium cation $\left(\mathrm{Mg}^{2+}\right)$ and then the driving force should be given by the $\Delta C_{\mathrm{Al}_{2} \mathrm{O}_{3}}{ }^{13,18,20,21)}$

The values of viscosity used for this analysis are the ones calculated using the model proposed by Riboud ${ }^{22}$ at the dissolution temperature $\left(1500^{\circ} \mathrm{C}\right)$. Table 4 shows the calculation of driving force, the calculated viscosity and total dissolution time for a $100 \mu \mathrm{m}$ particle. The total dissolution time can be explained by looking at both the driving force and the viscosity. In Table 4 it can be seen that both tundish slags have similar total dissolution times due to combined decrease in both viscosity and $\Delta C$ when $\mathrm{MgO}$ is added to the slag.

In Fig. 6, the total dissolution time is plot as function of $\Delta C / \eta$. The trend shows that as expected, the dissolution time (in seconds) decreases with an increasing ratio of $\Delta C / \eta$ with a relation shown in Eq. (13). In this equation, the units of $\Delta C$ are $\left(\mathrm{kg} \cdot \mathrm{m}^{-3}\right)$ and of $\eta[\mathrm{Pa} \cdot \mathrm{s}]$. The results by Monaghan et al. ${ }^{21)}$ using a similar technique on slags with high silica are also shown in the graph.

$$
\tau=\frac{2.04 \times 10^{-2}}{\Delta C / \eta} .
$$

For particles of arbitrary sizes (radius $=R_{0}$ ), one can by assuming the validity of Eq. (13), modify Eq. (15) by a factor: $\left(R_{0}(\mu \mathrm{m}) / 100\right)^{2}$. For most of these experiments, the diffusing specie is the aluminum anion and then the parameter ' $a$ ' in the Stokes-Einstein relation is constant. The exception is the dissolution of $\mathrm{MgO}$. The fact that the dissolution time, in the tundish slag, of $\mathrm{MgO}$ is shorter than the dissolution time of $\mathrm{Al}_{2} \mathrm{O}_{3}$ (Table 4), suggests that when the driving force and the viscosity are similar, the dissolution time of $\mathrm{MgO}$ is faster and it is evident that the size of the magnesium cation should be smaller than the aluminum anion (Eq. (14)).

Figure 7 shows the parameter $\Delta C / \eta$ calculated for the liquid region of the $\mathrm{Al}_{2} \mathrm{O}_{3}-\mathrm{CaO}-\mathrm{SiO}_{2}$ phase diagram at $1600^{\circ} \mathrm{C}$. The values were dividing in 4 regions. The best dissolution rate for $\mathrm{Al}_{2} \mathrm{O}_{3}$ will be close to saturation with lime where the $\mathrm{SiO}_{2}$ is minimum and hence the viscosity too, as well as $\Delta \mathrm{C}$ for saturation with $\mathrm{Al}_{2} \mathrm{O}_{3}$ is maximum.

\section{Conclusions}

The abilities of slags to capture common oxide inclusions have been investigated. In terms of slag properties, it 


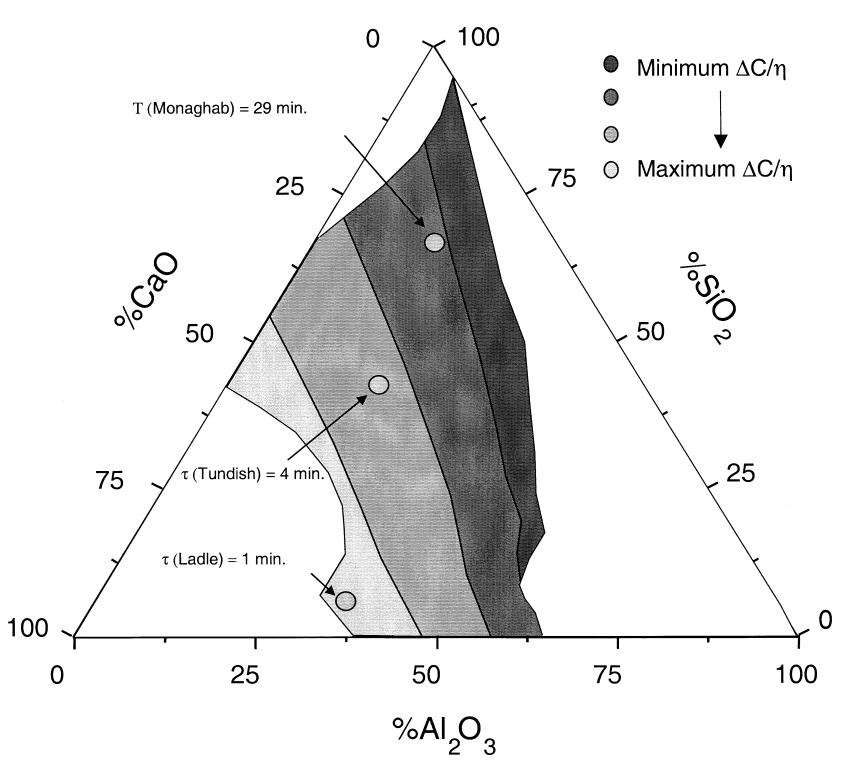

Fig. 7. Schematic of the distribution of $\Delta C / \mathrm{h}$ on the liquid slag at $1600^{\circ} \mathrm{C}$ for the $\mathrm{Al}_{2} \mathrm{O}_{3}-\mathrm{CaO}-\mathrm{SiO}_{2}$ system.

was found that:

(1) In the inclusion separation process the most critical property was inclusion/slag interfacial energy, followed by slag viscosity.

(2) A sensitivity analysis showed that the separation process was rapid enough to be ignored unless the slag/interfacial tension exceeded $0.8 \mathrm{~N} / \mathrm{m}$ for the ladle and mold slags, and $0.41 \mathrm{~N} / \mathrm{m}$ for the tundish slag, which is unrealistic for inclusions that are expected to dissolve in the slag.

(3) The dissolution of inclusions appears to be inversely proportional to a ratio between super-saturation and slag viscosity $(\Delta \mathrm{C} / \eta)$ For the dissolution of $100 \mu \mathrm{m} \mathrm{Al}_{2} \mathrm{O}_{3}$ or Spinel inclusions, the total dissolution time in seconds is:

$$
\tau=\frac{2.04 \times 10^{-2}}{\Delta C / \eta}
$$

\section{Acknowledgements}

Financial support from the National Science Foundation under the CAREER grant DMR 0348818 is greatly acknowledged.

\section{REFERENCES}

1) B. G. Thomas and L. Zhang: ISIJ Int., 41 (2001), 1181.

2) Y. Miki and B. G. Thomas: Metall. Mater. Trans. B, 30B (1999), 639.

3) P. Kozakevitch and L. Lucas: Rev. Metall., 65 (1968), 589.

4) P. Kozakevitch and M. Olette: Rev. Metall., 68 (1971), 636.

5) P. Kozakevitch and M. Olette: Proc. Int. Conf. Production and Application of Clean Steel, The Iron and Steel Institute, London, (1970), 42.

6) P. V. Riboud and M. Olette: Proc. 7th Int. Conf. on Vacuum Metallurgy, ISIJ, Tokyo, Japan, (1982), 879.

7) A. W. Cramb and J. Jimbo: W. O. Philbrook Memorial Symp., ISS, Warrendale, PA, (1988), 259.

8) V. F. Chevrier: Overview of Doctoral Thesis, Department of Materials Science and Engineering, Carnegie Mellon University, (1999).

9) S. Hartland: Thin Liquid Films, Fundamentals and Applications. Surface Science Series, Vol. 29, ed. by I. B. Iuvanov, Marcel Dekker Inc., New York, (1988), 50.

10) D. Bouris and G. Bergeles: Metall. Mater. Trans. B, 29B (1998), 641.

11) K. Nakajima and K. Okamura: 4th Int. Conf. on Molten Slags and Fluxes, ISIJ, Tokyo, (1992), 505.

12) S. Feldbauer and A. W. Cramb: Proc. 13th PTD Conf., ISS, Warrendale, PA, (1995), 327.

13) M. Valdez, K. Prapakorn, A. W. Cramb and S. Sridhar: Steel Res., 72 (2001), 291.

14) M. Valdez, K. Prapakorn, A. W. Cramb and S. Sridhar: Ironmaking Steelmaking, 29 (2002), 47.

15) S. Sridhar and A. W. Cramb: Metall. Mater. Trans. B, 31B (2000), 406.

16) A. B. Fox, M. E. Valdez, J. Gisby, R. C. Atwood, P. D. Lee and S. Sridhar: ISIJ Int., 44 (2004), 836

17) O. Levenspiel: Chemical Reaction Engineering, 3rd ed., Chapter 25, John Wiley \& Sons, (1999), 566.

18) Slag Atlas, 2nd ed., Verlag Stahleisen GmbH, Germany, (1995).

19) H. Towers: Trans. Br. Ceram. Soc., 53 (1954), 180.

20) B. Monagahn and L. Chen: J. Non-Crys. Solids, 347 (2004), 254.

21) B. Monagahn, L. Chen and J. Sorbe: Ironmaking Steelmaking, 2 (2005), 258.

21) K. Mills and B. Keene: Int. Mater. Rev., 32 (1987), 1. 